\title{
Quantifying the impact of release operations and weather conditions on the flow and temperature dynamics in the cascade-reservoir system
}

\author{
Gang Chen ${ }^{1, a}$, Yue Zhai ${ }^{1}$, Hui Fan ${ }^{2}$, Xing Fang ${ }^{3}$ and Chuanhai Wang ${ }^{1}$ \\ ${ }^{1}$ College of Hydrology and Water Resources, Hohai University, Nanjing 210098, China \\ ${ }^{2}$ Hydrology Bureau of Haihe River Water Conservancy Commission, Ministry of Water Resources, Tianjin, 300170, China \\ ${ }^{3}$ Department of Civil Engineering, Auburn University, Auburn, AL 36849, USA
}

\begin{abstract}
The objective of this study was to investigate the flow dynamics and temperature characteristics under different reservoir operation scenarios and weather conditions in the river-reservoir system, which can be used to set scientific guidelines for river management and conservation planning strategies. The calibrated three-dimensional model provided simulated unsteady water surface elevation, temperature, velocity and discharge at different layers (depths) in different locations. A series of operation scenarios were modeled to understand and quantify formation, propagation, and disappearance of density currents that are resulted from combinations of daily repeated large release (DRLR) of different durations and solar heating. DRLRs (140 $\mathrm{m}^{3} / \mathrm{s}$ ) with longer durations pushed the bottom cold water further downstream and maintained the bottom water temperature cooler. Variations of weather conditions (e.g., drops of air temperature and solar radiation) directly controled variations of bottom-layer water temperature. The daily drop rate of bottom temperature was related to the rate and duration of air temperature drop. Under the practice for the water turbines running at downstream, it clearly showed the shocking withdrawal and stopping effect from the downstream operation. The velocity for the whole cross-section were almost increased with same magnitude of about $0.1 \mathrm{~m} / \mathrm{s}$ at GOUS and JML.
\end{abstract}

\section{Introduction}

Riverine ecosystems worldwide face multiple pressures due to human interventions such as dams, channelization, deforestation, and irrigation, as well as a plethora of industrial and agricultural waterborne emissions $[1,2,13]$. One major physical stressor on riverine ecosystems is thermal discharge from industrial facilities, which is not only problematic in and of itself but also can aggravate the effects of chemical and biological pollution $[4,7]$. Anthropogenic excess heat, discharged as cooling water from power plant, has been recognized as a form of pollutions in lakes, reservoirs, and rivers since the middle of the twentieth century [3,11]. Power plants stationed along rivers employ two main types of cooling systems, named once-through and recirculation cooling. In oncethrough cooling systems the heat absorbed by the cooling water during the steam cycle is directly rejected back into the river [10].

River regulation as a means of water resources management is a common operating procedure all over the world. The alteration of upstream inflow into the river can be responsible for changes in flow and thermal dynamics [8,12]. Weather is also one of the most important physical factors that affect water temperature in the natural system. Many climate and environmental parameters can also possibly affect water temperature in streams/rivers, for example, solar radiation, relative humidity, wind speed, water depth, groundwater inflow, artificial heat inputs, and thermal conductivity of the sediments $[6,9]$

In the study, we tried to quantify the effect of climatic condition, release operations and thermal discharge to the natural river. Various upstream reservoir releases (management/operation patterns) were used to understand the unsteady flow patterns and temperature distributions in a river-reservoir system in Alabama, USA (Fig. 1). The three-dimensional (3D) Environmental Fluid Dynamics Code (EFDC) model [5] was configured and calibrated for different purposes below.

(1) Understanding flow dynamics and density current from the calibrated EFDC model which provided simulated unsteady water surface elevation, temperature, velocity and discharge at different layers (depths) in different locations.

(2) A series of upstream reservoir operation scenarios were modeled to understand and quantify formation, propagation, and disappearance of density currents that are resulted from combinations of colder small releases, daily repeated large release (DRLR) of different durations from upstream reservoir operation, and solar heating.

(3) Considering climate variations (warming or cooling scenarios), the upstream reservoir management scenarios to control the downstream water temperature for the power plant were further studied.

(4) The different downstream reservoir operations (water turbines running or the gate opening) were

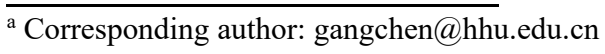


modeled to analyze the backwater effect in the cascadereservoir system.

\section{Study area}

The study dealed with model simulations of flow and thermal dynamics in a river-reservoir system (124.2 river $\mathrm{km}$ ) starting from Smith Dam Tailrace (SDT) to Bankhead Lock\& Dam (BLD, about $23.5 \mathrm{~m}$ height and $426.7 \mathrm{~m}$ long) in Alabama (AL), USA (Figure 1). The river reach from upstream to downstream includes Sipsey Fork $(21.9 \mathrm{~km})$, the lower Mulberry Fork $(70.6 \mathrm{~km})$, and a reservoir segment $(31.7 \mathrm{~km})$ of Bankhead Lake. Sipsey Fork and the lower Mulberry Fork are the riverine portions of Bankhead Lake. The Black Warrior River is formed about $40 \mathrm{~km}$ west of Birmingham, AL, by the confluence of the Mulberry Fork and the Locust Fork, which join as arms of Bankhead Lake, a narrow reservoir formed by constructing BLD in 1963. The study area is referred here as the Bankhead river-reservoir system (BRRS).

The water releases from Smith Dam to BRRS is normally $2.83 \mathrm{~m}^{3} / \mathrm{s}$, but during late spring, summer, and early fall, large amount of intermittent water releases is practiced to meet peak electric generating demand. Based on 2011 release data, average flows during the intermittent release periods ranged from 104.0 to 273.5 $\mathrm{m}^{3} / \mathrm{s}$ with average and median flows about $140 \mathrm{~m}^{3} / \mathrm{s}$. In $2011,60.1 \%$ of the intermittent releases from SDT had a duration from 2 to 6 hours, and most of the releases started around 1:00 pm. The percentages of all 2011 releases with durations of about $2 \mathrm{hr}, 4 \mathrm{hr}$, and $6 \mathrm{hr}$ are $5.2 \%, 15.5 \%$ and $14.6 \%$, respectively. Therefore, we used the intermittent daily large releases with these three durations $(2,4$, and 6 $\mathrm{hr}$ ) for the sensitivity analysis. During the normal water releases, water depths in Sipsey Fork range from 2.16 to $4.55 \mathrm{~m}$, in the lower Mulberry Fork from 4.71 to $11.47 \mathrm{~m}$, and in the Bankhead Lake from 12.12 to $17.73 \mathrm{~m}$. The water surface elevation at Bankhead L\&D is typically about $77.66 \mathrm{~m}$ (with relatively small variations) above mean sea level. The monitoring stations and selected cross sections for result analysis are shown in Figure 1 and summarized in Table 1 including abbreviation used thereafter and description.

Table 1. Abbreviation and description of cross sectional locations used in the study (Figure 1).

\begin{tabular}{|c|c|}
\hline Abbreviation & Description \\
\hline BLD & $\begin{array}{c}\text { Bankhead Lock \& Dam (downstream } \\
\text { boundary of EFDC model) }\end{array}$ \\
\hline Cordova & $\begin{array}{c}\text { USGS }^{1} \text { monitoring station at Cordova on } \\
\text { the lower Mulberry River }\end{array}$ \\
\hline GOUS & Monitoring station upstream the power \\
\hline MSF & Middle cross section of Sipsey Fork \\
\hline River intake & Withdrawal location near the power plant \\
\hline SDT & $\begin{array}{c}\text { Smith Dam tailrace (upstream boundary of } \\
\text { EFDC model) }\end{array}$ \\
\hline
\end{tabular}

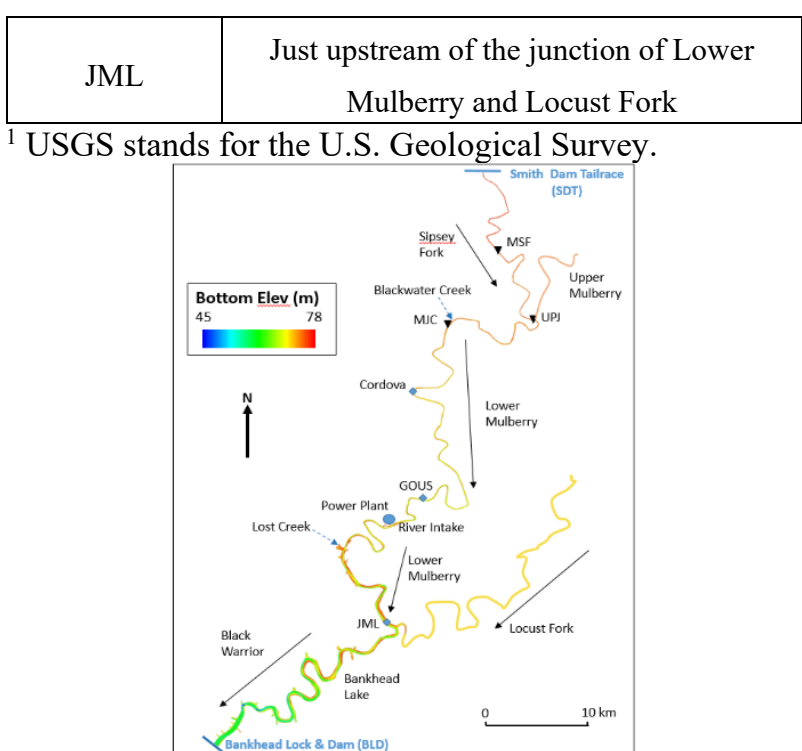

Figure 1. Color contours of the bottom elevation showing Sipsey Fork, the lower Mulberry Fork, and Black Warrior River as study area

\section{Phenomenon for flow dynamics and density current}

The large upstream reservoir releases resulted in not only complex flow variations in natural river, but also complex temperature dynamics and distributions. The calibrated model was applied first to analyze the phenomenon of flow dynamics and density current. After a large release (6 hours) on June 7, 2011, the distributions of water surface elevation and temperature along the channel centerline at BRRS from SDT to GOUS are showed at three different times: (a) 1 hour after the large release started, (b) 4 hours after the large release stopped, (c) about 18 hours after the large release stopped. The water surface elevation increased from less than $78 \mathrm{~m}$ (a normal condition similar to that in Figure 2 (c) just before the next large release) to about $82 \mathrm{~m}$ at SDT at 13:15 (Figure 2(a)). The flow momentum pushed colder water downstream about $9 \mathrm{~km}$ which is close to the middle of Sipsey Fork (MSF). There were temperature stratifications downstream the MSF because of solar heating and backwater effect (flow) from BLD (Figure 2 (a)). The effect of flow momentum seemed to reach GOUS which is about $64 \mathrm{~km}$ downstream from SDT (Figure 2 (b)) at 4 hours after the release stopped. The water surface elevation dropped to $79.25 \mathrm{~m}$ at SDT.

It shows there was almost no thermal stratification from SDT to GOUS because of mixing effect of flow momentum during the large release and no solar heating during the night. As the large flow momentum with colder water pushed warmer water in BRRS downstream, there were temperature gradients from SDT $\left(\sim 12^{\circ} \mathrm{C}\right)$ to GOUS $\left(\sim 20^{\circ} \mathrm{C}\right)$. Figure 2 (c) shows after the large release stopped for 18 hours, the temperature stratifications were developed almost everywhere at 11:45 on June 8, which just gave temperature distribution less than 1 hour before the next large release on June 8 . The water surface elevations were almost same $(77.63 \mathrm{~m})$ from SDT to GOUS when there was no large release effect. The small 
constant inflow $\left(2.83 \mathrm{~m}^{3} / \mathrm{s}\right)$ after the large release still pushed the cold water downstream, but the density current near SDT moved very slowly and did not have obvious effect on water movement further downstream. The coldwater current (blue color) near SDT just moved about 3 $\mathrm{km}$ over 18 hours of small flow release.
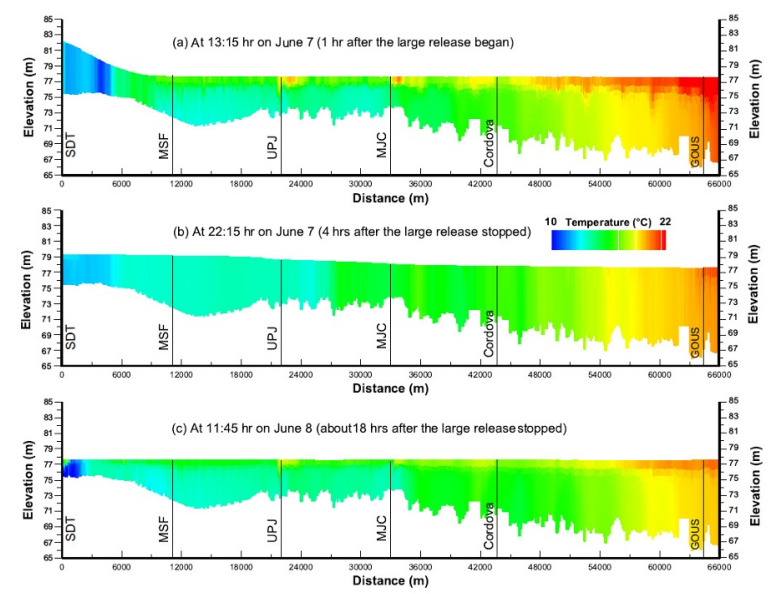

Figure 2. Distributions (contours) of simulated temperature along the channel centerline of BRRS from SDT to GOUS at three different times after a large release on June 7, 2011: (a) 1 hour after the large release started, (b) 4 hours after the large release stopped, and (c) about 18 hours after the large release stopped.

\section{Sensitivity analysis of upstream operations}

Large upstream releases do have the effect on the downstream water temperature. But how to quantify the relationship between upstream release and downstream temperature decrease? Sensitivity model ran for 2-hr, 4hr, and 6-hr DRLRs, the results for constant small release (CSR) only for comparison are showed in Figure 3. At MSF, which is close to SDT, surface and bottom water temperatures were well mixed during each DRLR (Figure 3 (a)). Simulated water temperatures kept constant for a few hours during the night. When the sun rises in the next day, the surface water temperature increases gradually because of the solar heating. The water temperatures at MSF were a little bit cooler for the longer repeated release (Figure 3 (a)). DRLRs could have lasting impacts on water temperatures in the surface (Figure 3 (b)) and bottom (Figure 3 (c)) layers at Cordova. Simulated surface temperatures at Cordova had certain daily variations due to solar heating and cooling (diurnal effects), but maintained lower average temperatures instead of gradually increasing with time during the simulation period.

As a whole, average bottom temperatures at Cordova were lower for longer duration of DRLRs: $19.63{ }^{\circ} \mathrm{C}$ for the 4-hr DRLR and $18.24{ }^{\circ} \mathrm{C}$ for the 6-hr DRLR. For bottom temperatures at Cordova, the 4-hr and 6-hr DRLRs could maintain lower water temperatures with small daily variations, but still had the gradual increase with time for the 2-hr DRLR temperatures. The bottom temperatures simulated with the 4-hr and 6-hr DRLRs were higher than temperatures under CSR for the first 68 days because cooler bottom water temperatures were mixed with warmer surface temperatures by the large flow momentum. Simulated bottom temperatures at Cordova under the 2-hr DRLR were larger than ones under CSR in the first 14 days, but became lower afterwards, which eventually exhibited the effect of DRLR.

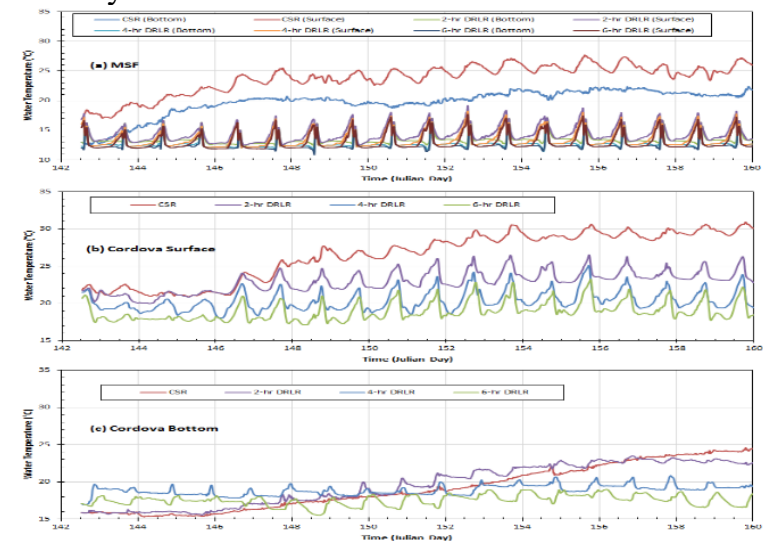

Figure 3. Time series of simulated water temperatures in the surface and bottom layers at MSF and Cordova for CSR only, 2-, 4-, and 6-hr DRLRs.

\section{Combination of weather conditions and DRLRs}

Combined with weather conditions, water temperature would show more interesting results under different upstream operations. There are time series of simulated bottom-layer water temperatures at GOUS and the river intake for the 2-hr, 4-hr, and 6-hr DRLRs over the whole simulation period (May 4 to August 12) with the 11-day drop-rise weather scenario from June 13 to 23 in Figure 4. There were the stationary weather conditions before and after the 11-day drop-rise period.

Simulated daily mean bottom temperatures on June 13 at GOUS under the stationary weather and 2-, 4- and 6-hr DRLRs were respectively $19.9,19.1$, and $18.4{ }^{\circ} \mathrm{C}$. It is shown that the weather change scenario with constant $2{ }^{\circ} \mathrm{C}$ /day air temperature drop-rise in 11 days resulted in bottom-layer water temperature drops and rises over 2458 days in GOUS and the river intake. The beginning and end days of the lower temperature duration were defined when simulated temperature under the drop-rise scenario was $0.1{ }^{\circ} \mathrm{C}$ lower than that under the stationary weather scenario. During the 11-day drop-rise weather scenario, the bottom temperature under 6-hr DRLRs started to drop firstly with 3 days' delay, following with the drop under 4-hr and 2-hr DRLRs (5 and 7 days' delay). These differences in delaying the bottom-layer water temperature drop were due to stronger momentum and pushing effects of longer duration of the DRLRs. The overall drop rates for bottom-layer temperature were almost same $\left(3.7-3.9^{\circ} \mathrm{C}\right.$ total decrease from June 13 to the day when the lowest temperature appeared) for 2-hr, 4-hr and 6-hr DRLRs because the same drop rate of air temperature was used. The lowest daily mean bottom temperatures were $16.2,15.2$, and $14.7^{\circ} \mathrm{C}$ for the 2-, 4-, and 6-hr DRLRs before the bottom temperature gradually increased to the temperature under the stationary weather 
scenario. Under the 2-, 4-, and 6-hr DRLRs, the 11-day drop-rise weather scenario resulted in 52, 38, and 24 days (4.7-2.2 times longer than the 11-day drop-rise period) of lower bottom-layer water temperature at GOUS. Simulated temperature dynamics was complex at GOUS: temperatures under 6-hr DRLRs were higher than ones under 2- and 4-hr DRLRs for the first 24 and 26 days, respectively, but lower for remaining days, under the same initial conditions and weather conditions.

Under 2-hr DRLRs, the bottom-layer water temperature at the river intake (Figure 4 (b)) on June 12 was about $2{ }^{\circ} \mathrm{C}$ higher than one at GOUS because the river intake is near the power plant and 2-hr DRLR has relatively weaker momentum or push effect. Whereas, on account of stronger momentum effect, the bottom temperature on June 12 at the rive intake under 6-hr DRLRs was $0.5^{\circ} \mathrm{C}$ lower than one at GOUS. Under 2-hr, 4-hr, and 6-hr DRLRs, the lowest bottom-layer water temperatures during dropping and rising period were 18.8 , 15.4 , and $14.1^{\circ} \mathrm{C}$ with the cooler duration 58 (June 14August 10), 37 (June 15-July 21), and 26 (June 14-July 9) days, respectively. The lower temperature duration was short for 4- and 6-hr DRLRs, but the total temperature decrease was large $\left(3.8-3.9{ }^{\circ} \mathrm{C}\right.$ comparing with $3.2{ }^{\circ} \mathrm{C}$ under 2-hr DRLRs). During the lower temperature durations, the average temperatures at the river intake under 2-hr, 4-hr, and 6-hr DRLRs were 21.4, 18.2, and $16.5^{\circ} \mathrm{C}$.And during the whole simulation period,20.6, 18.3 , and $17.2{ }^{\circ} \mathrm{C}$, respectively. If the lower water temperature is needed for the power plant, it can be achieved by releasing more water when the cold air is coming.
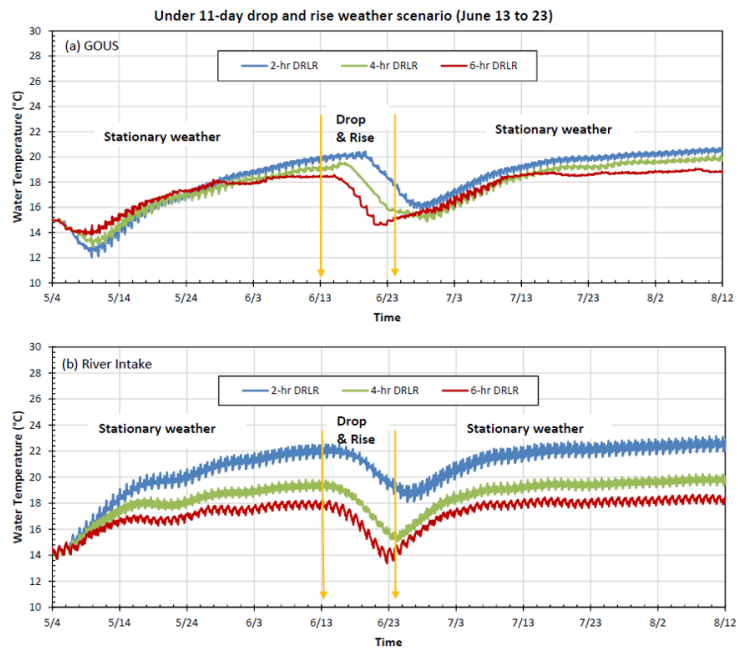

Figure 4. Time series of simulated bottom temperatures at (a) GOUS, and (b) river intake with the 11-day drop and rise weather scenario for the 2-hr, 4-hr, and 6-hr DRLRs from June 13 to 23 over the whole simulation period (May 4 to August 12). It also includes the stationary weather conditions before and after the 11-day drop and rise weather scenario period.

\section{Backwater effect}

Figure 5 shows simulated vertical velocity profiles under four different downstream operations at the centerlines of GOUS ((a) and (c)) and JML ((b) and (d)) when DRLR at SDT last 4 hours at two different time: 2 hrs before release and 4-hr release just stopped. The velocity in positive (negative) means flow moved from upstream (downstream) towards downstream (upstream). Visually, the velocities at GOUS and JML at two different times show the similar pattern under constant WSE and when the gate is open due to the similar downstream management. Likewise, there are similar velocity variations under two water turbines operations.

At $2 \mathrm{hrs}$ before upstream release, the upstream release and downstream turbines were both shutdown for more than 16 hours. Hence, there was no much effect at GOUS or JML from the operations. The velocities for 4 different cases show the similar patterns and magnitudes. At the time of upstream release just stopped, the velocities at GOUS and JML were increased due to the upstream momentum. The velocity for the main water body increased at GOUS, however, it only shows the increase for the surface layer at JML. It proves the surface wave from the large momentum moves fastest in different layers. Besides the upstream influence, the downstream operation plays another part in the flow dynamics of BRRS. Under the practice for the water turbines running at downstream, it clearly shows the shocking withdrawal and stopping effect from the downstream operation. The velocity for the whole cross-section from bottom and surface layers were almost increased with same magnitude of about $0.1 \mathrm{~m} / \mathrm{s}$ at GOUS and JML (Figure 5 (c) and (d)), compared with operations of opening gate and constant WSE.
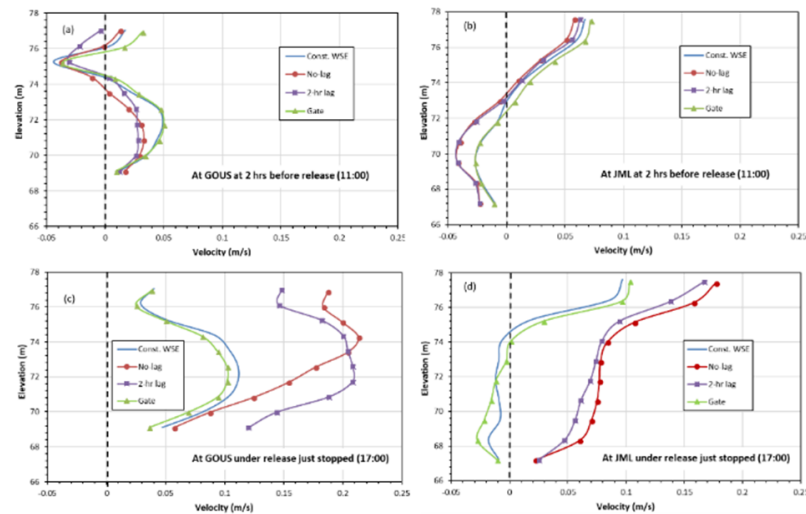

Figure 5. Simulated vertical velocity profiles under 4 different downstream boundary conditionsat the centerlines of GOUS (a and c) and JML (b and d) at two different time: at 2 hrs before 4-hr release (11:00) and when the 4-hr release just stopped (17:00), when DRLRs at SDT last 4 hrs.

It's obvious that the water temperature in the BRRS was changed by the upstream release operations. However, temperature variation was not that strong as flow dynamics under different downstream operations. When the thermal flow returns to the natural river, the flow dynamics will show more effect on the water temperature changes. Figure 6 shows surface and bottom temperature at GOUS under four different operations. The flow momentum under the operations of water turbines running were larger comparing with the operations when gate was open or under constant WSE, which made the temperature at whole cross section more mixed. The bottom temperature was more stable under different downstream operations. The bottom temperature for turbines running was a little bit higher when the gate was open or under 
constant WSE, which is due to the mixing effect from the larger flow dynamics.

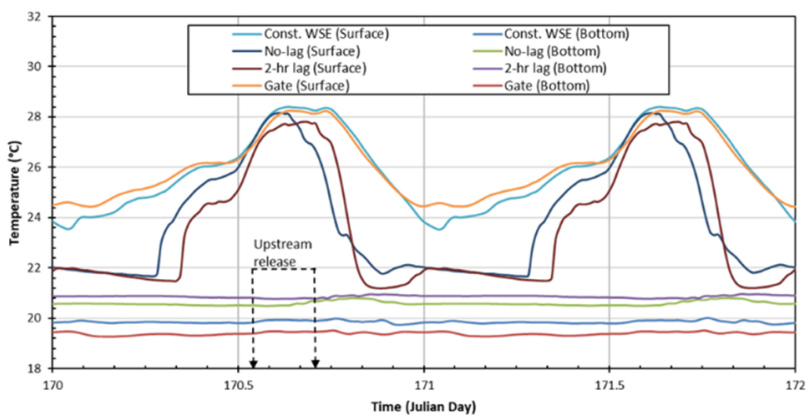

Figure 6. Simulated temperature at GOUS under 4 different cases for surface and bottom layers.

\section{Conclusions}

Both the duration of large releases and solar heating affect and control the formation and spread of density currents. The density currents in BRRS form at different reaches, are destroyed at upstream locations due to the flow momentum of the releases, and form again due to solar heating. Overall, the average surface and bottom temperatures were lower for longer duration of DRLR. The daily drop rate of bottom temperature was related to the rate and duration of air temperature drop. Bottomlayer water temperature could maintain cooler conditions for a longer period than the surface temperature did. Under different downstream reservoir operations, water turbines running at BLD pushed more water downstream than the gate opening. Temperature variation was not that strong as flow dynamics under different downstream operations.

\section{Acknowledgment}

This research has been financially supported by the National Key Research and Development Program of China (2018YFC0407900) and the Fundamental Research Funds for the Central Universities (2017B05814).

\section{Author Contributions}

Authors collaborated together for the completion of this work; the paper was written by Gang Chen; Gang Chen and Xing Fang reviewed and improved the manuscript with comments; and data compilation and statistical analysis were completed by all authors.

\section{Conflicts of Interest}

The authors declare no conflict of interest.

\section{References}

1. B SE, A AH, ENVIRON MANAGE, 30,492 (2002)

2. C D, FRESHW SCI,51,1389 (2006)

3. D JA, F TJ, WATER RESOUR RES,10,67 (1974)
4. EH H, AJ H, T D, NM vS, W A, CRIT REV TOXICOL, 31,247 (2001)

5. H JM, The College of William and Mary, Virginia Institute of Marine Science, Gloucester Point, VA (1992)

6. J AC et al. Sci Total Environ, 407,4787(2009)

7. $\mathrm{M} \mathrm{H}$ et al. SCI TOTAL ENVIRON, 408,3746 (2010)

8. M WL, Journal of the Hydraulics Division, 98,1031 (1972)

9. P JM, F X, S HG, J AM WATER RESOUR AS, 34,1109 (1998)

10. R CE, V Vliet MTH, P S, ENVIRON RES LETT 11,104011(2016)

11. S CR, WATER RESOUR RES, 11,180 (1975)

12. S BA, G JS, J HYDRAUL RES, 38,339 (2000)

13. $\mathrm{S}$ BW et al, P NATL ACAD SCI USA $\mathbf{1 0 1}, 14132$ (2004) 